\title{
LEITURA MULTIMODAL DO POEMA ESCRÍNIO, DE MANOEL DE BARROS
}

\author{
MULTIMODAL READING OF THE POEM ESCRINIO, \\ BY MANOEL DE BARROS
}

\author{
LECTURA MULTIMODAL DEL POEMA ESCRÍNIO, \\ POR MANOEL DE BARROS
}

Mariana Silva SANTOS; Rauer Ribeiro RODRIGUES.

RESUMO:

A valorização da modalidade escrita dentro da sociedade contemporânea - intensa, e, muitas vezes, exclusiva - tem recebido inúmeras críticas de estudiosos que defendem haver limitação de significados produzidos como consequência dessa realidade. Nessa perspectiva, este trabalho tem por objetivo uma análise intersemiótica entre o poema Escrínio e as fotografias do início do século passado, representativas dos espacos mencionados no texto literário. Tal proposicãa se respalda na possibilidade de alargamento de significados produzidos a partir da leitura em diversas modalidades, incrementadas com a discussão sobre o papel da fotografia (BARTHES, 2015) Enquanto as fotos revelam pontualmente a realidade de uma cidade em seu esplendor, vivido no início do século $X X O$ poema satiriza tal visão (CAMPOS, 2011), retratando e enaltecendo lugares e pessoas várias vezes marginalizadas pelos jornais corumbaenses da época (SOUZA, 2008).

PALAVRAS-CHAVE:

Análise; Fotografia; Leitura multimodal; Poesia Brasileira.
ABSTRACT:

The intense and often exclusive valuation of written form within contemporary society has received countless criticisms from scholars who argue that there is a limitation of meanings produced as a consequence of this reality. So from this perspective, this work aims at an intersemiotic analysis between the poem "Escrinio" and the photographs of the beginning of the last century, representative of the spaces mentioned in the literary text. This proposition is supported by the possibility of broadening the meanings produced by reading in various modalities, which are further enhanced by the discussion about the role of photography (Barthes, 2015). While the photos reveal the reality of a city in its splendor, lived in the beginning of the 20th century, the poem satirizes such a vision (CAMPOS, 2011), portraying and extolling places and people several times marginalized by corumba's newspapers of the time (SOUZA, 2008).

\section{KEYWORDS:}

Analysis; $\quad$ Photography;

Multimodal Reading; Brazilian Poetry.
RESUMEN:

La valoración de la modalidad escrita dentro de la sociedad contemporánea, intensa $y$, muchas veces, exclusiva, ha recibido innumerables críticas de estudiosos que defienden haber limitación de significados producidos como consecuencia de esa realidad. En esta perspectiva, este trabajo tiene por objetivo un análisis intersemiótico entre el poema "Escrio" y las fotografías del inicio del siglo pasado, representativas de los espacios mencionados en el texto literario. Esta proposición se respalda en la posibilidad de ampliación de significados producidos a partir de la lectura en diversas modalidades, incrementadas con la discusión sobre el papel de la fotografía (BARTHES, 2015). Mientras las fotos revelan puntualmente la realidad de una ciudad en su esplendor, vivida a principio del siglo XX, el poema se burla de esta visión (CAMPOS, 2011), discribiendo y enalteciendo lugares y personas muchas veces marginadas por los diarios corumbaenses de la época (SOUZA, 2008).

PALABRAS-LLAVE: Análisis; Fotografía; Lectura multimodal; Poesía Brasileña. 


\section{INTRODUÇÃO}

Segundo Roger Chartier (1999), a pluralidade do texto não é desfeita pelas imposições dos significados impostos, seja pelas intenções do autor, seja pelas instâncias de prestígio; na verdade, para o historiador, "[...]um texto só existe se houver leitor para the dar significado" (CHARTIER, 1999, $s / n)$.

A liberdade dada a figura do leitor, contudo, não é arbitrária, ele ainda é condicionado pela comunidade, formas discursivas e materiais do texto. Dessa maneira, a construção do sentido no processo de leitura sofre diversas interferências, entre elas dos espaços legíveis forma onde se configura o texto - e da efetuação - o próprio ato de leitura. Embora essas características não sejam consideradas fundamentais, ajudam a modelar as expectativas do leitor. Seguindo essa linha de raciocínio entendese que o leitor de Barros cercado por textos encadernados não terá a mesma interpretação do leitor que lança mão da tecnologia para suas leituras, e muito menos produzirá significado semelhante ao leitor que tem ao seu alcance referências visuais das localidades mencionadas nos poemas, como é o caso do leitor dessa pesquisa.

Estudamos o significado de Corumbá na poesia de Manoel de Barros, para proporcionar uma maior compreensão das referências espaciais feitas nos textos poéticos, conscientes, no entanto, que sua poesia não se trata de um retrato fiel, mas uma recriação e uma sublimação da realidade. Nestes termos, sua representação imagética que cria um locus próprio tendo por referência a região do Pantanal segue as lições milenares da Arte Poética de Aristóteles (2011, passim), para quem a mimese é recriação do real a partir de princípios de verossimilhança - a catarse aristotélica não se configura, no entanto, e se torna uma espécie de epifania, uma descoberta uma iluminação de facetas inesperadas do real entrevistas poeticamente por Manoel de Barros.

Neste artigo, buscamos analisar como a urbes Corumbá é apresentada nas fotos tiradas no início do século passado, período no qual Barros viveu na região, em contraste à maneira como a cidade é representada no poema Escrínio. As fotos auxiliam na construção de um texto multimodal e muito mais visual, que possibilita ao leitor de Barros (re)conhecer o local, de forma a expandir os possiveis significados criados quanto ao poema.

Ao trabalhar com uma mídia antiga, a fotografia, essa pesquisa propõe uma análise intersemiótica do poema. A proposta de analisar a representação de Corumbá em fotos da primeira metade do século passado foi feita não apenas por se tratar do período em que o jovem Manoel de Barros residiu na cidade, mas também por ser pouco anterior à criação e publicação do livro Poemas Concebidos Sem Pecado (1937), obra que contém o texto selecionado como objeto de estudo dessa pesquisa: o poema Escrínio, escolhido por conter muitas referências espaciais de corumbá

Além disso, como forma de complementar essa análise intersemiótica, acreditamos ser necessário a discussão do papel da fotografia, justificando, dessa maneira, a escolha por essa mídia para o trabalho, mas primeiro debatendo sobre as mudanças que a tecnologia pode trazer para a leitura dos textos. E, como essa pesquisa está ligada ao estudo da representação de um local verídico dentro de uma obra literária, nesse caso a cidade em que o próprio autor cresceu e viveu por tanto tempo, vislumbramos ser necessário a inserção de uma breve biografia e o debate sobre o regionalismo dentro dos escritos de Barros, tema muitas vezes polêmico quando relacionado ao autor.

De maneira geral, a crítica mais universitária mais recente sobre a obra de Manoel de Barros considera que o referente geográfico que informa seu universo poético é transmutado em um locus próprio, específico, sem configurar as características tradicionais do regionalismo na literatura brasileira, qual sejam, a linguagem que emula o falar local, típico, as personagens que caracterizam um tipo específico, distinto dos demais, a evocação em clave eufórica e laudatória da realidade natural (ver, por exemplo, MARCHEZAN, 2009, e RODRIGUES;

GRÁCIARODRIGUES, 2013). Um estudo interessante sobre a natureza do Pantanal em Barros, e que homologa o que afirmamos acima, é o de Kelcilene GráciaRodrigues (2017): Manoel de Barros elabora "poesia de significação que subverte o real, em ótica transgressora, para revelar a essência do poético" (GRÁCIA-RODRIGUES, 2017, p. 185).

Por seu lado, Luiz Gonzaga Marchezan enfatiza que o conceito de regionalismo surge para "localizar no tempo manifestações literárias voltadas para a representação de valores 
rurais, em diferentes quadros territoriais" (MARCHEZAN, 2009, p. IX). Trata-se do primeiro regionalismo, de meados do século XIX, que apresenta "vozes advindas de diversos lugares discursivos" (MARCHEZAN, 2009, p. XLI), todas voltadas para o homem e - cenário rural, muitas vezes apresentando "o homem rústico do campo como objeto curioso, exótico" (MARCHEZAN, 2009, p. XLII). Já Rauer Ribeiro Rodrigues e Kelcilene GráciaRodrigues traçam, em "Fortuna e infortúnios do regionalismo", panorama "da transformação do conceito de regionalismo no âmbito da literatura brasileira" (RODRIGUES; GRÁCIARODRIGUES, 2013, p. 263). Consideram que o conceito deriva de "fatos culturais e históricos, antes que naturais", o mostram o motivo pelo qual o conceito e sua antiga aplicabilidade vem sendo questionada por autores de meados do século $X X$ a nossos dias (RODRIGUES; GRÁCIARODRIGUES, 2013, p. 287-288).

Em específico sobre a poesia de Manoel de Barros, consideram que ela "sempre desfigura o mundo, desvelando-o insólito", em movimento que "desfigura a desfiguração e reempreende a construção do mundo a partir de um movimento simultâneo ao nascimento da linguagem", o que perfaz "um logos edificado sob o signo do desformar" (RODRIGUES; GRÁCIARODRIGUES, 2013, p. 284-285).

É nesta clave, em que a mimese aristotélica cede lugar a um movimento instaurador de um universo próprio, de referencialidade específica, mas rarefeita, que buscamos os espaços naturais e urbanos evocados por Manoel de Barros, os fotografamos e analisamos o cenário dos poemas.

\section{ESPAÇO E FOTOGRAFIA}

A revolução tecnológica que vem ocorrendo nas últimas décadas traz mudanças inclusive para o mundo do livro. Em consequência da alteração do suporte, já que do códex os textos podem passar a ser lidos nas telas, modificam-se as condições de recepção e compreensão do mesmo, o que repercute na construção de sentido feita pelo leitor (CHARTIER, 1999). Jenkins (2009) complementa que a transição pela qual a sociedade está passando repercute ainda no "funcionamento das religiões, da educação, do direito, da política, da publicidade e mesmo do setor militar" (JENKINS, 2009, p. 31) e, seria consequência do surgimento da "Cultura de Convergência". Eis como ele elucida o conceito:

Por convergência,
refiro-me ao fluxo de
conteúdos através de
múltiplas plataformas
der mídia, à
cooperacão entre
múltiplos mercados
midiáticos e do
comportamento
migratório dos
públicos dos meios de
comunicacão, que vão
a quase qualquer
parte em busca das
experiências
entretenimento que
desejam. (JENKINS,
2009, p. 30).

De fato, no mundo contemporâneo, com maior frequência e mais claramente, se percebe uma participação de outras mídias durante a nossa leitura, não limitando-se aos gêneros convencionais como a reportagem, onde é possivel interagir em grande parte dos casos com textos verbais e não verbais simultaneamente. Em verdade, na atualidade, também têm se presenciado não só as adaptações fílmicas das narrativas- presentes desde do século passado, mas também adaptações em jogos, passagem para suportes eletrônicos das mesmas, entre outras transições e interação de plataformas.

As mudanças pelas quais o mundo contemporâneo está passando inelutavelmente trará inúmeras consequências, inclusive na maneira como a leitura é efetivada. O conceito predominante de leitura, ligado exclusivamente com a escrita, deve sofrer modificações, levando-se em conta a maneira pela qual os gêneros textuais vêm sendo construídos, com imagens, e demandando a participação do leitor, principalmente, em textos multimodais, onde a escrita verbal-textual pode não ser o centro para a comunicação. Essas mudanças, contudo, não precisam significar necessariamente um abandono dos clássicos, como um dia criticou Perrone (1998), mas talvez uma alteração nos significados produzidos e forma de apresentação.

Em resumo, a interação com o livro, da forma como foi conhecida por tanto tempo parece fadada ao desaparecimento, não implicando a extinção da leitura, como já se temeu, mas uma inevitável alteração de como essa atividade é feita:

Os textos
contemporâneos
passaram a ser
hibridos
multissemióticos, isto
é, mesclam modos de
linguagem, midias e
suportes, o que
acarreta mudancas na
comunicacão, na




$\begin{array}{lrl}\text { construcão } & \text { de } & \text { autor, ou mesmo outro leitor. } \\ \text { narrativas, } & \text { na } & \text { Mais uma vez, essa proposta de } \\ \text { organização } & \text { do } & \text { interação entre gêneros } \\ \text { pensamento e na } & \text { distintivos não busca a limitação } \\ \text { apropriação } & \text { dos da compreensão, mas sua } \\ \text { saberes. } & \text { (GOMES, expansão. }\end{array}$

2017, p. 14).

Em relação a esta pesquisa, a fim de entender quais vantagens a convergência de mídias poderia proporcionar dentro da literatura, optou-se para além do livro, a fotografia, por ser ela responsável, antes de tudo, por mostrar com acuidade o "Isso-Foi", repetindo mecanicamente o que jamais poderá repetir-se existencialmente, reduzindo o corpus buscado ao corpo mostrado (BARTHES, 2015). Ou seja, ela não pode ser modificada ou modificar o objeto registrado, possuindo sempre algo de tautológico, já que "um cachimbo nela, é sempre um cachimbo, intransigentemente" (BARTHES, 2015, p. 15).

Segundo Barthes (2015) uma fotografia será sempre alvo de três práticas: fazer, suportar, olhar. Em outras palavras, haverá sempre o Operador, o fotógrafo, o Spectator, aquele que vê a foto e, por fim, o Spectrum, nada mais do que o objeto, o referente. Por isso, a fotografia a que o Operador estava ligado poderia se diferenciar daquela vista pelo Spectador, já que o primeiro a tinha visto através do buraco da câmera enquanto o segundo, em sua revelação química. Esse contraste reitera o fato de que mesmo que o leitor tenha acesso às fotografias da época, ainda não será o mesmo que ter a visão do fotógrafo que as tirou, da mesma forma que o sujeito com um texto em mão provavelmente não terá a mesma experiência e entendimento da obra que seu
Através dos poemas que evocamos neste estudo, o leitor de Manoel de Barros tem acesso a evidências de que alguns dos espaços mencionados em seus poemas realmente existiram; observa, ademais, que, apesar de inegavelmente sofrerem transformações ao se modificarem em espaços poéticos, ainda assim sua ambientação física concreta existiu a serviço do interesse de qualquer um que deseja vê-las e compará-las ao mundo criado pelo poeta.

É interessante também delimitar o tipo de foto selecionada, e essa é a foto unária a mais adequada para os objetivos visados, por ser aquela que transmite enfaticamente a realidade, tendo como a unidade sua principal característica, não trazendo distrações ou distúrbios (BARTHES, 2015). Em outras palavras, elas não foram criadas com a intenção de causar alguma reflexão, assim como as fotos de reportagens ou pornográficas.

As fotos aqui inseridas, contudo, podem deixar de ser unárias dependendo daquele que as observa. Pois elas, falando de modo subjetivo, além do studium - elemento que parte da cena, e chama atenção do indivíduo, nos causaram também o punctum - uma picada ainda mais funda, seria o acaso de uma foto que punge e fere concomitantemente (BARTHES, 2015) devido a menção ao texto poético e à ligação emocional que temos com a cidade. Contudo, para entender essa relação entre Corumbá e o poeta, e a existência de tantas referências aos locais, acreditamos ser interessante levantar uma pequena biografia e também uma reflexão sobre a polêmica temática regionalista apontada em seus escritos, o que será desvelado mais detalhadamente na próxima seção.

\section{BARROS E CORUMBÁ}

Nascido em 19 de dezembro de 1916, Manoel Wenceslau Leite de Barros, reconhecido nacionalmente por Manoel de Barros, e para os íntimos como Nequinho, foi levado para Corumbá com apenas dois anos de idade, e logo em seguida para uma fazenda do seu pai na Nhecolândia, dois territórios muito próximos.

Corumbá já foi uma das cidades mais populosas em Mato Grosso, recebendo o título de município em 1878. Desde o início do século $X X$, foi marcada por uma combinação de mercados europeus e norteamericanos em 1856, o que também possibilitou a redução o tempo gasto em trânsito entre a região e o corte no Rio de Janeiro.

Barros mudou-se para Campo Grande para ter mais oportunidades educacionais com somente oito anos, em seguida, pela mesma razão seguiu para o Rio de Janeiro. Apesar do desejo da família em dar-lhe as melhores oportunidades, a sua paixão para a educação surgiu somente quando ele entra em contato com os sermões de Antônio Vieira., como mencionado no poema Parrede!:

Quando eu estudava no colégio, interno, Eu fazia pecado solitário. 
Um padre me pegou

fazendo.

- Corrumbá, no parrrede! Meu castigo era ficar em pé defronte a uma parede e decorar 50 linhas de um livro.

O padre me deu pra decorar o Sermão da Sexagésima de Vieira. - Decorrrar 50 linhas, o padre repetiu.

O que eu lera por antes naquele colégio eram romances de aventura, mal traduzidos e que me davam tédio.

Ao ler e decorar 50 linhas da Sexagésima fiquei embevecido.

E li o Sermão inteiro. Meu Deus, agora eu precisava fazer mais pecado solitário!

E fiz de montão.

- Corumbá, no parrrede!

Era a glória.

Eu ia fascinado pra parede. Desta vez o padre me deu o Sermão do Mandato.

Decorei e li o livro

alcandorado.

Aprendi a gostar do equilibrio sonoro das frases.

Gostar quase até do cheiro das letras.

Fiquei fraco de tanto cometer pecado solitário.

Ficar no parrrede era uma glória.

Tomei um vidro de fortificante e fiquei bom. A esse tempo também eu aprendi a escutar o silêncio das paredes.

\section{(BARROS, 2010, p. 27)}

Seu retorno ao lugar de maior planície alagada no mundo, no entanto, apenas ocorreu com o óbito do seu pai, tendo que assumir a fazenda, Manoel conseguiu fazer com que ela the provê a renda necessária para "ficar à toa que significa o seguinte, eu ficar à disposição da poesia, então eu comprei o ócio, aí que eu pude ser o vagabundo profissional, como eu sou agora" (BARROS, 2009).

Em relação a sua poética, alguns traços são bem marcantes, como: a infância, o regionalismo e o carinho pelo inútil. Manoe brincava com as palavras, representando não só as crianças, como os bêbados e os loucos, o que o tornou um poeta detentor de uma linguagem original e chamativa (CAMPOS, 2011).

Além disso, a maior parte de suas obras trazem memórias da infância, momento tão valorizado que o próprio Barros chega a alegar apenas ter vivenciado a infância, tanto que seu livro Memórias Inventadas está dividido em primeira, segunda e terceira infância e, essa foi vivida no Pantanal, talvez por isso, seja um local tão citado e descrito não só em Poemas Concebidos Sem Pecado, mas na grande maioria dos seus trabalhos que trazem as características do lugar. Apesar dessa afirmação, o próprio Manoel, em algumas entrevistas, postula não ser um poeta regionalista, nem ter como objetivo exaltar o Pantanal e suas particularidades:

Minha poesia é
fertilizada pelo
Pantanal, mas a
palavra não serve a
mim para descrever
paisagem. Poesia não
é um fenômeno de
paisagem, é um
fenômeno de
linguagem. Eu sou
nascido no Pantanal,
sou filho do Pantanal,
gosto do Pantanal,
tenho amor pelo
Pantanal, sou criado
no Pantanal, o que me
dá dinheiro, o que me

dá o ócio é o Pantanal. Mas eu sou um poeta da palavra, e ninguém quer entender isso (...), que eu não sou poeta de paisagem, não sou poeta ecológico, não quero fazer folclore, não quero expressar costumes, não sou historiador. Eu sou poeta! Poeta é um ser que inventa. Eu invento o meu Pantanal. (BARROS, 2009).

Talvez essa recusa em se afirmar regionalista seria devido ao desagrado que muitas obras desta categoria trazem ao leitor muitas vezes por serem estreitas, esquemáticas, pitorescas, superficiais e condensadas (CHIAPPINI, 1995). No entanto, a pesquisadora, Ligia Chiappini, afirma o potencial e o status de obras prima que esses textos podem alcançar ao superar as dificuldades do próprio projeto regionalista.

Além disso, Citelli, em seu artigo A poesia de Manoel de Barros: entre o regional e o universal, escreve: "Embora os lugares descritos mobilizem características pantaneiras, transcendem 0 ambiente regional constituindo espaço super-regional.". Utilizando-se da expressão espaço superregional criado por Antonio Candido para descrever a de Guimarães Rosa, entende-se que a poesia de Manoel de Barros supera o embate entre cidade versus campo, em que o ser posto a brigar não pertence a nenhum desses ambientes, tornando a obra universal.

No caso de Manoel, mesmo que não seja intencional, ainda sim, há muitos elementos espaciais e culturais exclusivos ou símbolos 
o lugar. A classificação de poeta regionalista pode ser alcançada partindo da definição sobre regionalismo que Chiappini expõe em Do Beco ao Belo: dez teses sobre o regionalismo na literatura:

O regionalismo é um fenômeno universal, com tendência literária, ora mais ora menos atuante, tanto como movimento- ou seja, como manifestação de grupos de escritores que

programaticamente defendem sobretudo, uma literatura que tenha por ambiente, tema e tipos de uma região rural, em oposição aos costumes, valores e gostos citadinos, sobretudo das grandes capitaisquanto na forma de obras que concretizem, mais ou menos livremente, tal programa, mesmo que independem da adesão explícita de seus autores. (CHIPPANI, 1995, p. 153).

É possível, portanto, enquadrar Manoel como um poeta regionalista, pois além do registro da fala típica da região, dos locais, de figuras importantes, em alguns textos, há um claro contraste entre os valores citadinos e campestres. Por exemplo:

10.

Pela rua deserta atravessa um bêbado comprido e oscilante como bambu assobiando...

Ao longo das calcadas algumas familias ainda conversam velhas passam fumo nos dentes, mexericando...

Nhanhá está aborrecida com o neto que foi estudar no Rio e voltou de ateu - Se é pra disaprender. não precisa mais estudar Pasta um cavalo solto no fim escuro da rua O rio calmo lá embaixo pisca luzes de lanchas acordadas

Nhanhá choraminga: - Tá perdido, diz que negro é igual com branco! (BARROS, 2010, p. 16).

Em especial, nessa amostra, é possivel perceber que os valores campestres representados pelas ideias de Nhanhá, a avó de Cabeludinho, que defende $\mathrm{O}$ cristianismo e o preconceito racial, é contrastado com os valores citadinos, personificados em Cabeludinho, então um jovem acadêmico.

\section{ESCRÍNIO-FOTOS E POEMA}

Nessa seção, é primeiramente exposto o poema, objeto de estudo, em seguida, um breve comentário sobre os ambientes espaciais de Corumbá mencionados no texto, para então a apresentação das fotografias referentes a tais locais para, por fim, podermos discorrer sobre as possíveis interpretações a partir dessa leitura multimodal.

\section{O ESCRINNIO}

Um poeta municipal já me chamara a cidade de escrínio.

Que àquele tempo encabulava muito porque eu não sabia o seu significado direito. Soava como escárnio. Hoje eu sei que escrínio é coisa relacionada com joia, Cofre de bugigangas..
Por aísim.

Porém a cidade era em cima de uma pedra branca enorme

E o rio passava lá embaixo com piranhas camalotes

Pescadores e lanchas carregadas de couros vacuns fedidos.

Primeiro vinha a Rua do Porto: sobrados remontados na ladeira, flamboyants, armazéns de secos e molhados E mil turcos babaruches nas portas comendo sementes de abóbora... Depois, subindo a ladeira, vinha a cidade propriamente dita, com a estátua de Antônio Maria Coelho, heróis da Guerra do Paraguai, cheia de besouros na orelha E mais o Cinema Excelsior onde levavam um filme de Tom Mix 35 vezes por mês. E tudo o mais.

Escrínio entretanto era a Negra Marigarida

Boa que nem mulher de santo casto:

Nhanhá mijava na rede porque brincou com fogo de dia

Mijo de véia não disaparta nosso amor, né benzinho? -Yes.

Um dia Nhanhá Gertrudes fazia bolo de arroz.

Negra Margarida socava pilão.

E eu nem sei o que fazia mesmo.

Veio um negro risonho e disse sem perder o riso: - Vãobora comigo, negra? E levou Margarida enganchada no dedo pra São Saruê

Daí eu fiquei naquele casarão que tinha noites de medo.

Nhanhá sonhava bobagens que eu fugi de casa pra ser chalaneiro no Porto de corumbá! 
O mijo de Nhanhá sentia, no pingar, um vazio inédito e fazia uma lagoinha boa no mosaico..

Desse tempo adquiri a mania de mirar-me no espelho das águas...

(BARROS, 2010, p. 19).

A cidade de Corumbá vista a partir do Rio Paraguai (Figura 01) parece estar localizada acima de uma pedra, e a primeira rua que segue partindo desse olhar é a Rua Manuel Cavassa, onde ainda há resquícios das casas e armazéns que um dia exibiram o que foi o apogeu da cidade. (Figura 03) Do lado esquerdo há uma ladeira, ladeira Cunha e Cruz, subindo por mais uma quadra, virando a direita, está localizada a Praça da Independência, (Figura 04) onde se encontra a estátua do Coronel Antônio Maria Coelho, também mencionado no poema, na mesma rua da praça ainda havia o Cine Excelcior, agora uma loja de eletrodomésticos (Figura 05).
FOTOS RELACIONADAS AOS ESPACOS REFERIDOS NO POEMA

Figura 01 - A cidade em cima de uma pedra branca

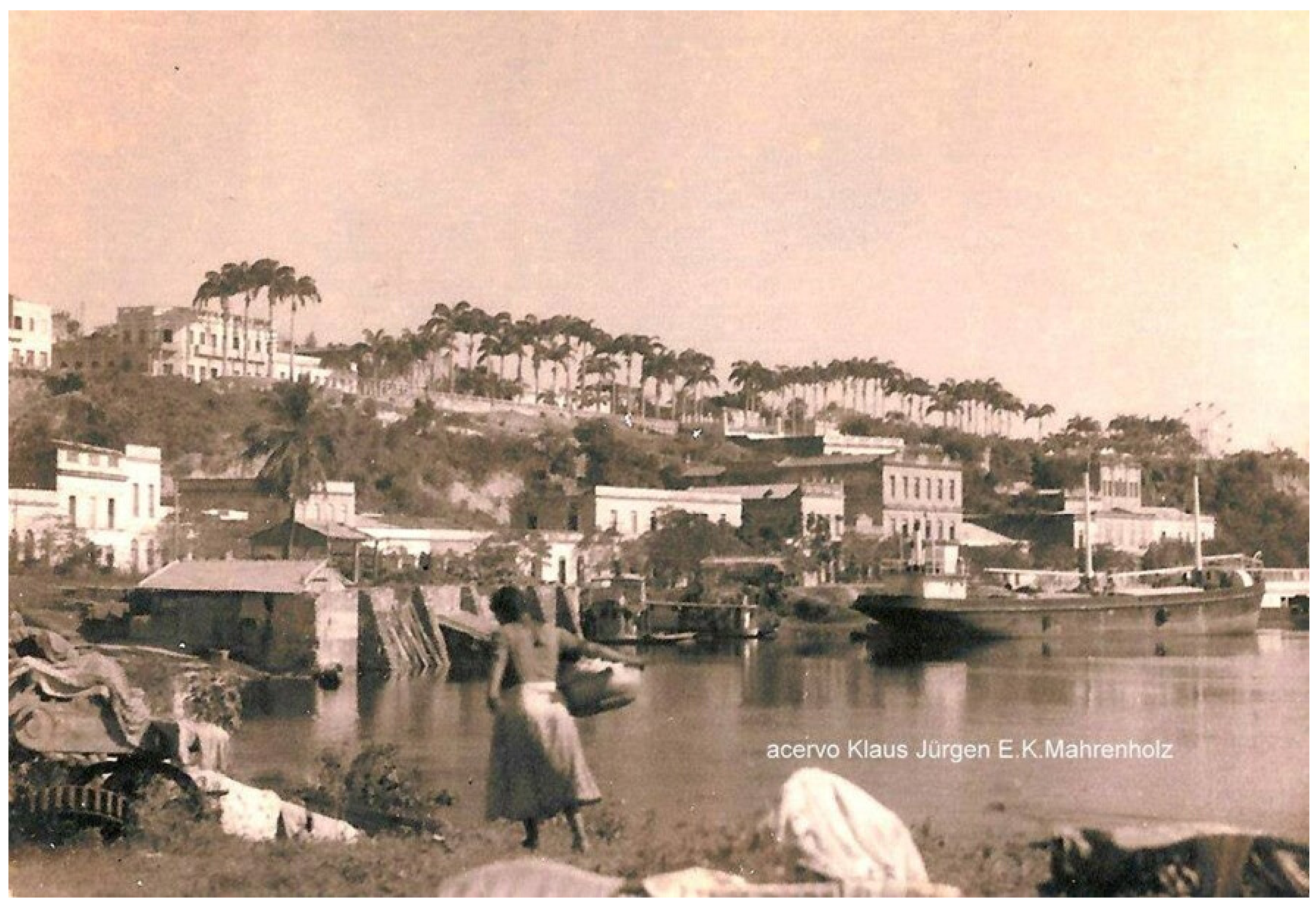

Fonte: Autoria Klaus Jürgen E.K. Mahrenhalz - Acervo do fotógrafo.

Figura O2 - Comércio de Peles, 1907

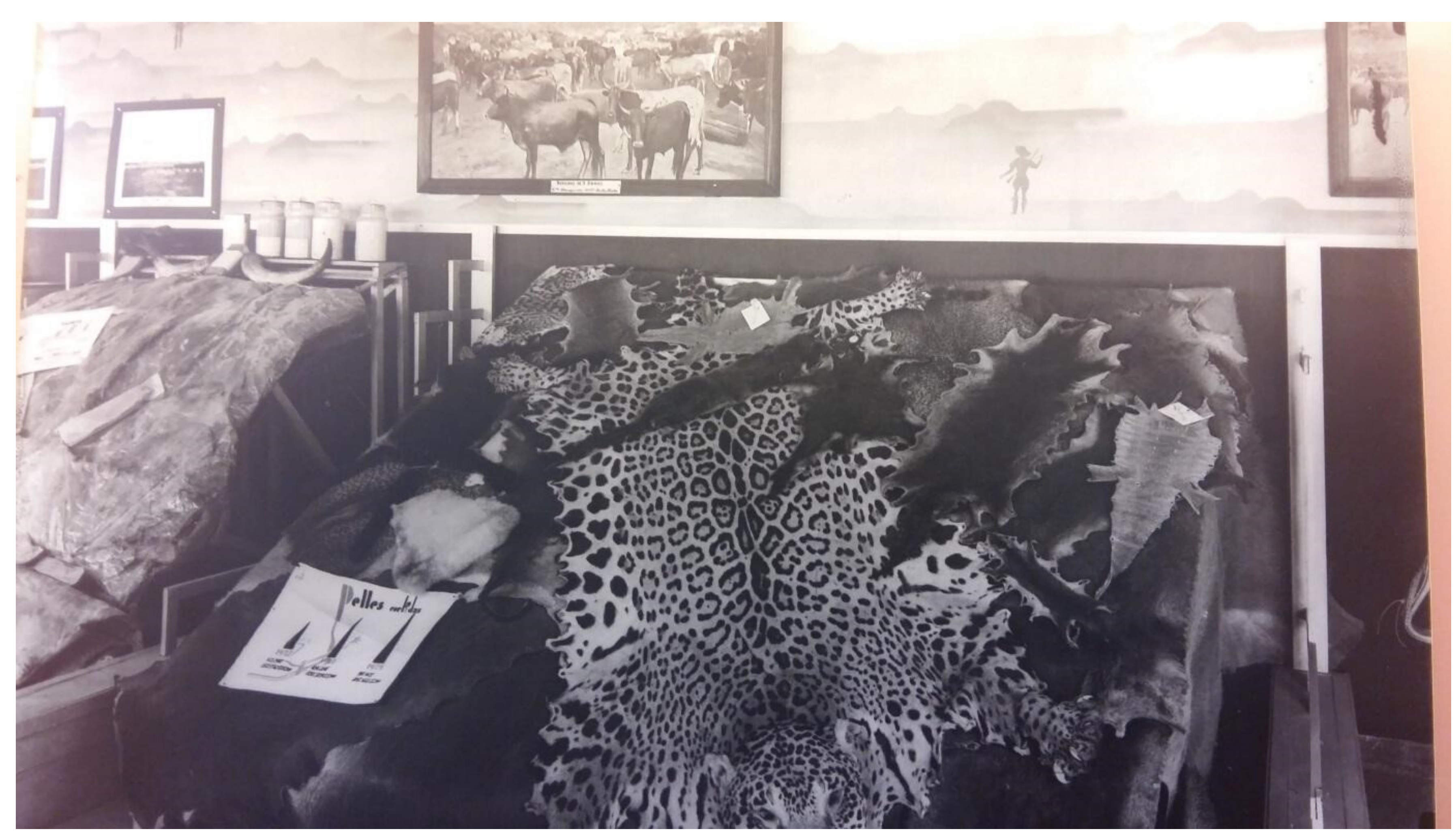

Fonte: Autoria desconhecida- Acervo do Museu do Pantanal- Museu do Índio, RJ

Figura O3 - Ladeira Cunha e Cruz

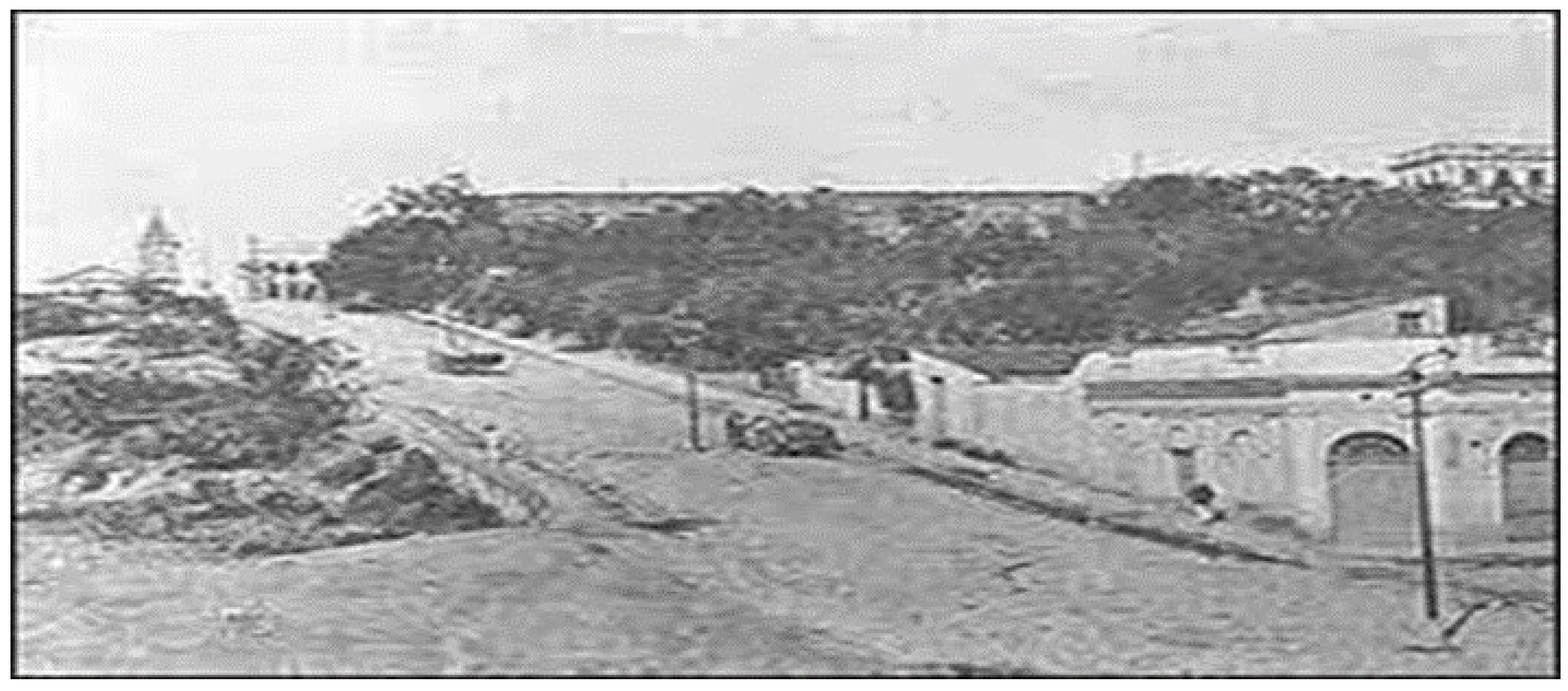

Fonte: Autoria desconhecida- Acervo Memórias de Corumbá (MS). 
Figura O4 - Jardim Público de Corumbá Mato Grosso

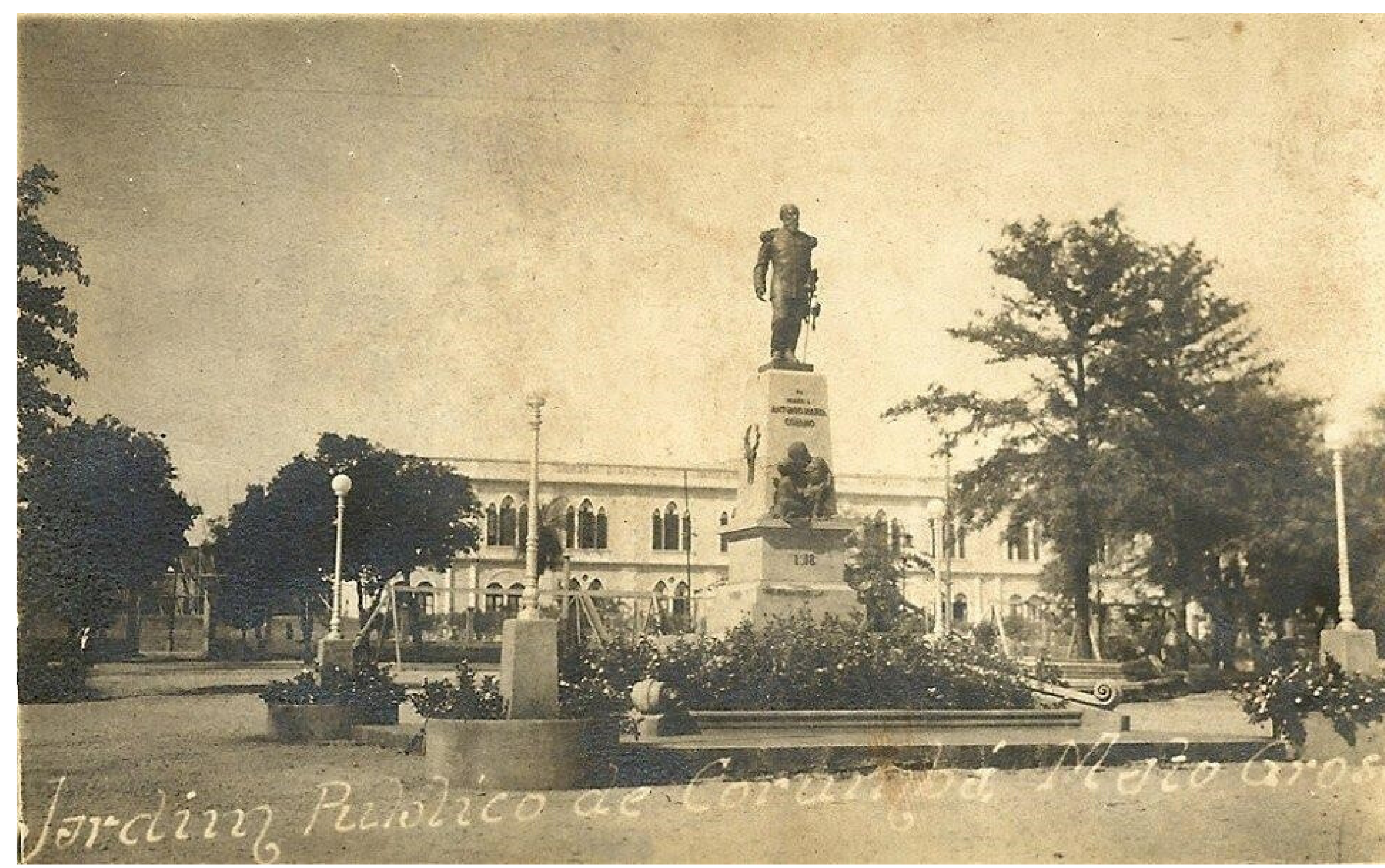

Fonte: Autoria desconhecida- Acervo Memórias de Corumbá (MS).

Figura 05 - Local do antigo Cine Excelcior

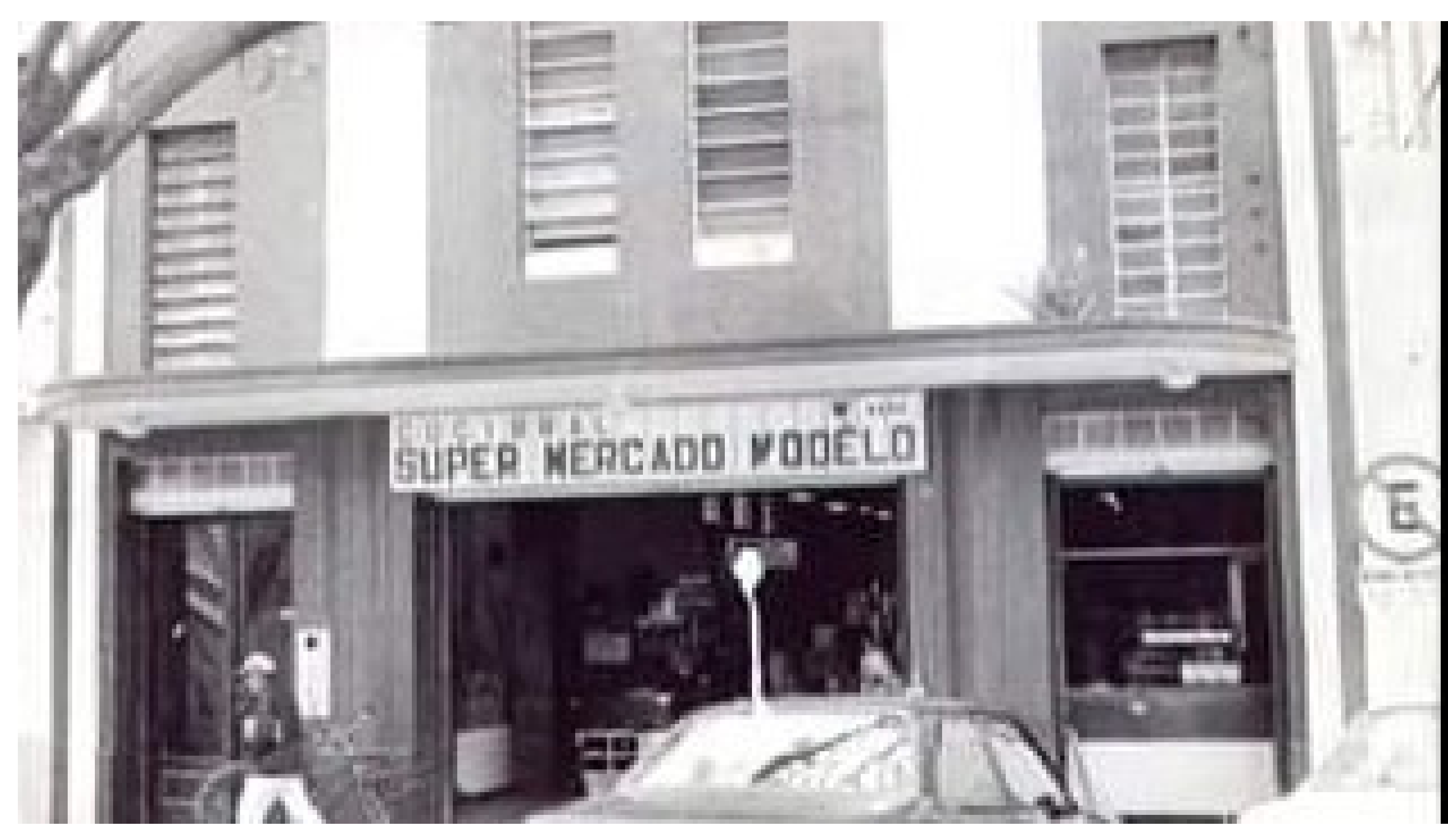

Fonte: Autoria desconhecida- Acervo Memórias de Corumbá (MS).

\section{ESCRÍNIO: SIGNIFICADOS CONSTRUÍDOS}

Os primeiros versos desse poema não metrificado, de rimas brancas, dão vida a narração de um eu-lírico que apresenta a sua cidade, admirando-a, quando faz uma menção de uma homenagem atribuída a ela, comparando a uma joia, a qual, contudo, de forma perspicaz, interliga não a um objeto genuinamente valioso mas a "bugigangas", essa crítica velada é seguida de uma descrição física detalhada do centro do município, a começar pelo porto, partindo de uma visão do Rio Paraguai.
Pela primeira foto selecionada é possivel compreender porque diz-se que a cidade parece estar acima de uma enorme pedra por ter sido construída sobre uma elevação montanhosa.

Essa fotografia é ainda mais representativa quando se atenta para a mulher segurando um balde, provavelmente portando roupas para serem lavadas à beira do rio, como era costumeiro das lavadeiras, um dos hábitos reprimidos pela alta sociedade da época, assim como o banho no lugar (SOUZA, 2008). Deve-se atentar ainda para o fato de que ao final do texto, Manoel afirma que o adjetivo escrínio-ou a joia como ele se refere, deveria ser atribuído a sua empregada e não ao local, como se a primeira fosse a verdadeira preciosidade, enquanto o segundo fosse mais uma pedra preciosa falsa- um cofre de bugigangas.

\section{Escrínio entretanto era a Negra Marigarida Boa que nem mulher de santo casto (BARROS, 2010, p. 19).}

Essa comparação é ainda mais interessante de ser enfatizada, quando o tempo e o espaço da escrita são analisados. A aparente naturalidade de ter um autor falando que uma negra é que era na verdade uma joia, não a cidade, perde-se quando o verso é contextualizado no início do século passado, no interior do Mato Grosso, quando o preconceito racial começava a ser subsidiado pelas ideias advindas das teorias raciais, que reforçavam e serviam para a manutenção das hierarquias após a abolição da escravatura (SOUZA, 2008).

O escrínio da Negra Marigarida, no entanto, também pode ser interpretado como uma menção erótica à iniciação sexual do eulírico, o que se reforça com o comentário de ela ser mulher mulher de santo casto, ou seja, de homem que não a satisfazia, e ela, ironicamente, como uma joia, entregava seu escrínio ao jovem. Lembremos que escrínio pode ser pequeno cofre, o que também vem a ser uma possível acepção para boceta.

Em comparação com a figura 01, percebe-se não apenas uma tentativa de capturar a beleza da cidade, focando na sua força econômica de então, o Rio Paraguai com as navegações, mas também no trabalho braçal, no caso, aquele que movido 
pelas lavadeiras, desprezadas juntamente com sua classe social pelos jornais da época, como comprava Souza (2008), mas digna de ser fotografada, como mostra-se na imagem, digna de ser exaltada, como no poema, neste caso, os dois textos se complementam e não excluem de seus registros a participação da mulher, trabalhadora, não só mais uma, mas alguém que merece estar ao centro da foto à frente da cidade, uma joia. É claro, devese deixar reforçado que são análises subjetivas e, por isso, os mesmos textos podem levar a outras abordagens e entendimentos.

Ainda, se o Rio Paraguai era para alguns o local para lavar roupa, tomar banho, realizar rituais religiosos sincréticos, em que um exemplo é o banho de Santo Antônio, que ocorre até os dias atuais, praticar pesca comercial, era ao mesmo tempo a maior fonte de riqueza para o local, por onde se importava e exportava produtos, como couros vacuns fedidos e secos molhados, como reitera a imagem 02. No começo do século passado, principalmente depois da Guerra do Paraguai, o Porto Geral se transformou em um importante ponto para troca e venda de mercadorias, fonte de renda não só para os brasileiros, mas também tantos outros imigrantes, como exemplo, os turcos mencionados no texto.

Ao final do século XIX

a população de

Corumbá contava com cerca de 20 nacionalidades

diferentes convivendo em torno de um intenso comércio regional internacional. Eram franceses, italianos, portugueses, sírios, libaneses, paraguaios,

macedônios, entre tantos outros. Suas atividades limitrofes estavam plenamente tomadas pela Bacia Platina, o que derivou um intercâmbio muito intenso com o Rio de Janeiro, além da Argentina, países da Europa e, também obviamente com o Paraguai. (OLIVEIRA, 2005, p. 351).

A diversidade, no entanto, não era celebrada, talvez por isso dentro de todos os arquivos revisados não foi encontrada alguma fotografia que pudesse representar a beleza cultural proporcionada pelo alto fluxo da imigração da época, o que também justifica o decreto do século passado que determinava a proibição de uso de outra língua, que não o português, já que essa parecia ser a menos utilizada quando comparada com o espanhol e a algumas línguas indígenas (SOUZA, 2008). Nesse caso, a existência de registros fotográficos dos produtos comercializados, mas não dos seus vendedores, nem das diversidades étnicas que enriquecia a cultura loca pudesse explicar o pensamento da época, em contraste com o do poeta, o qual um dia escreveu "Fazer o desprezível ser prezado é coisa que me apraz" (BARROS, 2010, p. 324).

Partindo para outro trecho do poema, ao mencionar a estátua de Antônio Maria Coelho parte da história bélica de Corumbá é ressuscitada. Durante a Guerra do Paraguai, o coronel Maria Coelho foi responsável pela retomada da cidade, como conta as referências de fotos disponíveis no MUHPAN, Museu do Pantanal:

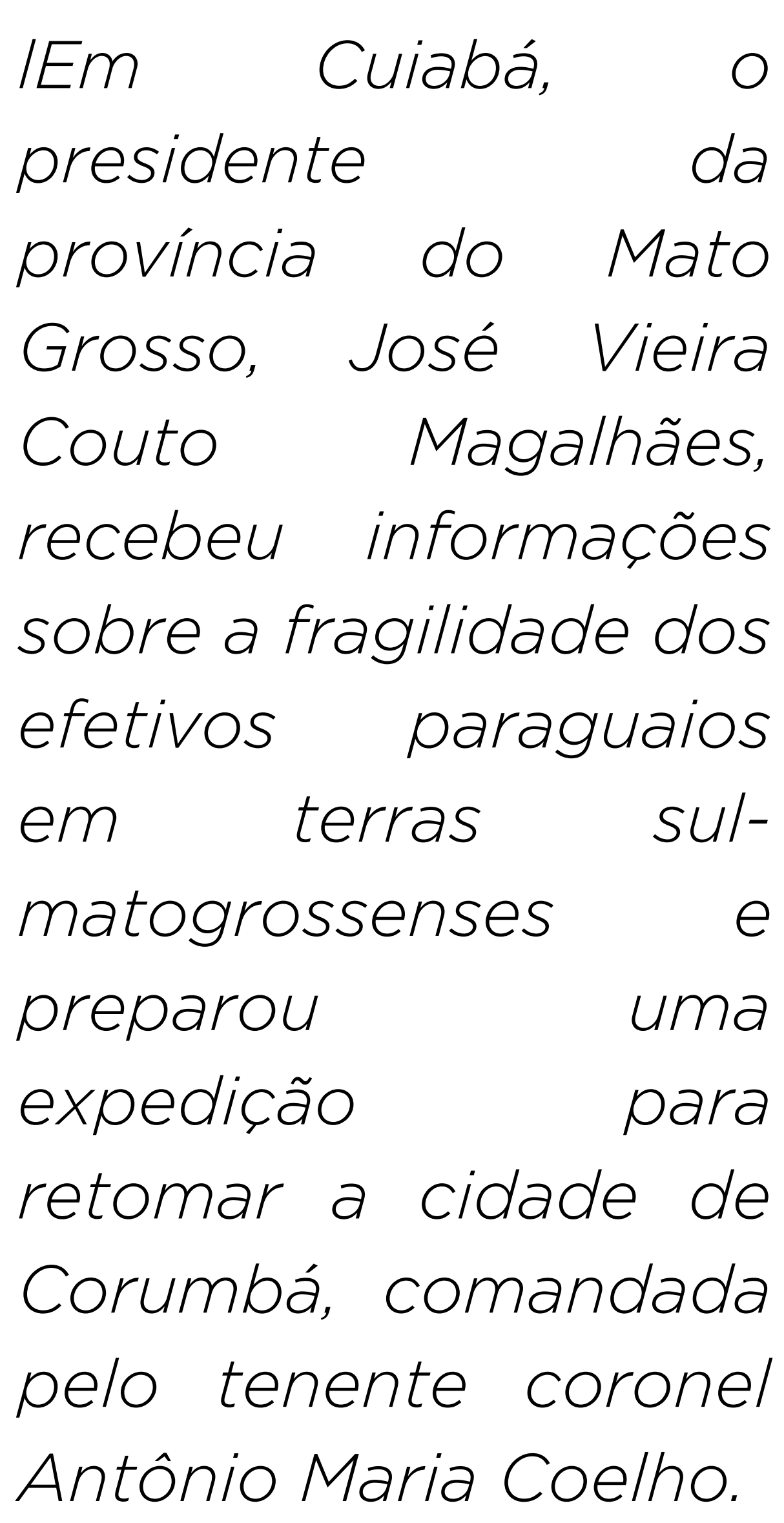

Apesar desse ato considerado por muitos como heroico, a menção da estátua rodeada por insetos como fez o autor levanta a possibilidade da interpretação dessa menção como uma crítica ao militar, ideia reforçada principalmente quando se compara o enxerto com Elegia 1938, de Carlos Drummond de Andrade:

Heróis enchem os parques da cidade em que te arrastas, e preconizam a virtude, a renúncia, o sangue frio, a concepção. $\dot{A}$ noite, se neblina, abrem guarda-chuvas de bronze Ou se recolhem aos volumes de sinistras bibliotecas (DRUMMOND, 2012, p. 137).

A estátua de Maria Coelho serviria, então, como inspiração para a população, um exemplo a ser seguido, mas que além de simbolizar a virtude e a renúncia, também representa o sangue-frio, aprofundando ainda mais essa linha de pensamento, esta estátua representa os homens de classes mais abastadas, que inquestionavelmente detêm o direito de tirar vidas e seguir aquilo que consideram virtudes, que devem ser seguidos sem questionamentos, pois são 
considerados heróis, ideia reforçada pela fotografia exposta em que se pode observar a imagem do coronel centralizada e de modo a ser observada de baixo para cima, acentuando seu poderio.

Por fim, o último local citado, hoje onde está localizado uma loja de eletrodoméstico, já foi um mercado como representa a foto selecionada, mas primeiramente foi palco para uma tela, foi o cinema Excelsior, construído na década de 30, exibiu os filmes de Tom Mix, nome artístico do ator americano Thomas Hezikiah Mix, estrela dos filmes de bang-bang. Na foto elegida observa-se a movimentação intensa que aquele comercio promovia, com carros estacionados, pessoas entrando e saindo, o que se pode contrastar com a possivel falta de clientes do cinema que foi fechado anos antes, dando ao local a possibilidade de vender produtos em vez de horas de entretenimento e arte. É claro, não deve se descartar a condição econômica da população, em geral desfavorável, como fator desse acontecimento, mas é interessante refletir, que até o ano de 2019, nenhum cinema conseguiu ser mantido no município, com uma população de pelo menos 100 mil pessoas e, sua primeira livraria foi fechada com poucos anos de abertura. A imagem, portanto, em especial para os cidadãos de Corumbá, pode levar a refletir sobre a sobreposição do capitalismo, do comércio, sobre a arte, o quanto o material parece ser mais apreciado do que qualquer tipo de manifestação artística.

\section{CONCLUSÃO}

O poema Escrínio por ser um dos textos que compõe de
Poemas Concebidos Sem

Pecado, com várias referências à infância do autor, traz em seu espaço poético referências espaciais da cidade em que Manoel de Barros residiu durante seus primeiros anos de vida.

Essa volta ao passado e a constante citação da região pantaneira, contudo, não se resume a atividade no âmbito do regionalismo literário, uma vez que Manoel recria o cenário local, não filtrado por uma lente fotográfica, mas pelos olhos criativos de um artista. Segue e mesmo transcende certa lição lapidar de Ligia Chiappini:

\section{[...] o grande escritor} regionalista é aquele que sabe nomear; que sabe o nome exato das árvores, flores, pássaros, rios e montanhas. Mas a região descrita ou aludida não é apenas um lugar fisicamente localizável no mapa do país. 0 mundo narrado não se localiza

necessariamente em uma determinada. região

geograficamente reconhecivel supondo muito mais um compromisso e geografia nacional. Trata-se, portanto, de negar a visão ingênua da cópia ou reflexo fotográfico da região. (CHIAPPINI, 1995, p. 158).

O contrário disso seria um regionalismo ingênuo, à maneira dos escritores do oitocentos, conforme descrevem Rauer Ribeiro Rodrigues e Kelcilene Grácia-Rodrigues (2013, p. 263290), sem absorção das lições dos mestres e inventores literários de um novo regionalismo, de meados do século $X X$ à primeira década do terceiro milênio. E Barros transcende àquele regionalismo não só porque não se fixa no típico, no rural, no linguajar localizado, mas porque cria um universo peculiar, imagético e de linguagem, em que a evocação do local busca a representação do homem contemporâneo.

Manoel representa Corumbá e seu bioma, ou seja, seu espaço físico, natural e biológico, não de forma denotativa, mas conotativa, através de uma linguagem única, exaltando os seres rejeitados, a minoria, confrontando tanto os valores impostos pela sociedade quanto os padrões exigidos pela língua culta. O Pantanal de Barros é o Pantanal em que os andarilhos, as putas e as crianças ganham voz, não apenas os ilustres coronéis ou os ditos "eruditos". Em que a força de econômica de uma cidade em pleno desenvolvimento não se compara a beleza de uma mulher, negra e em condição servil.

A Corumbá de Manoel, portanto, não se detêm aos aspectos físicos da cidade, nem ao progresso da região como se explicita nas fotografias da época. Os poemas são registros artísticos da cultura, do povo, das particularidades e peculiaridades da região.

A leitura multimodal abre o leque de interpretações dos versos de Manoel de Barros, contribuindo para a decifração do ambiente aos quais a lírica de Barros se referia, permitindo ao leitor uma noção da realidade na qual o poeta estava inserido, e ainda abre espaço para a reflexão sobre o município de Corumbá, incluindo questões 
socioeconômicas, com o que contribui para uma interpretação não apenas dos aspectos literários, mas também sociais, conteudistas, permitindo a construção de significados ainda mais enriquecidos.

\section{REFERENNCIAS}

\section{ARISTÓTELES. (2011). Poética.}

Trad. e notas Ana Maria Valente, prefácio Maria Helena da Rocha Pereira. Lisboa: Calouste Gulbenkian.

\section{BARTHES, Roland. (2015). A} câmera clara: nota sobre a fotografia/ Roland Barthes; tradução Júlio Castanõn Guimarães. - [ed. especial] - Rio de Janeiro: Nova Fronteira.

\section{BARROS, Manoel. (2009).}

[Depoimento]. In: CEZAR, Pedro. Só dez por cento é mentira: a desbiografia de Manoel de Barros. São Paulo: Artezanato Eletrônico

\section{CHARTIER, Roger. (1999). A} ordem dos livros: Leitores, autores e bibliotecas na Europa entre os séculos XIV e XVIII.I Roger Chartier; tradução de Mary Del Priori- Brasilia: Editora Universidade de Brasilia.

CHIAPINNI, Ligia. (1995). "Do beco ao belo: dez teses sobre o regionalismo na literatura". Estudos Históricos, Rio de Janeiro, v. VIII, n. 1, p. 153-159.
CITELLI, Adilson. (2009). "A poesia de Manoel de Barros: entre o regional e o universal". Revista eca, São Paulo, Comunicação \& Educação, v. XIV, n. 3, p. 127-133, set/dez.

GOMES, Natália Barros da Silva. (2007). Leituras multimodais de O mágico de OZ por alunos de 6- ano do ensino fundamental: possibilidade de um ensino pluralista de literatura/ Natália da Silva Gomes-Maringá.

GRÁCIA-RODRIGUES, Kelcilene. (2017). "Manoel de Barros: A palavra é um punhal que brilha, rasga e fere". Guavira Letras, Três Lagoas, MS, n. 24, p. 185 201, jan./jun. In

http://websensors.net.br/seer/in dex.php/guavira/article/view/67 6/467. Acesso em 16 Mai. 2019 .

\section{MARCHEZAN, Luiz Gonzaga.}

(2009). Introdução.

(Org.). O conto regionalista: do romantismo ao pré-modernismo. São Paulo: Martins

Fontes. P. IX-XLIII).

NAGATA, Aline Akemi. (2016).

"Esse jogo daria um ótimo livro: uma análise da literatura gamer e da constituição de práticas de leitura em narrativas transmidiáticas." 2015. 161 f. Tese (Doutorado em Educação) Faculdade de Educação da Universidade de São Paulo, São Paulo.

\author{
PERRONE-MOISÉS, Leyla. \\ (1998). Altas Literaturas. Escolha \\ e Valor na Obra Crítica de \\ Escritores Modernos. São Paulo: \\ Companhia das Letras.
}

\section{RODRIGUES, Raver Ribeiro;} GRÁCIA-RODRIGUES, Kelcilene. (2013). "Fortuna e infortúnios do regionalismo". In: Germana Sales e Roberto Acízelo de Souza (Orgs.). Literatura Brasileira: Região, Nação, Globalização. Campinas, SP: Pontes. p. 263290

souZA, João Carlos de. (2008) Sertão Cosmopolita: tensões da modernidade de Corumbá (1872- 1918. São Paulo: Alameda.

CAMPOS, Luciene Lemos de. (2010) "A mendiga e o andarilho - a recriação poética de figuras populares nas fronteiras de Manoel de Barros". $154 \mathrm{f}$.

Dissertação (Mestrado, Estudos Fronteiriços) - Universidade Federal do Mato Grosso do SulCampus do Pantanal, MS. 2011.

\section{OLIVEIRA, Marco Aurélio} Machado de. (2005). "Tempo, fronteira e imigrante: um lugar e suas 'inexistências'.". In: OLIVEIRA, Tito (Org.). Território sem limites. Campo Grande: UFMS. p. 349-358.

JENKINS, Henry. (2009). Cultura da convergência. São Paulo: Aleph.

(2010). Poesia

completa. São Paulo: Leya.

Recebido em 01 abr 2019 | Aprovado em 05 dez 2019

Mariana Silva SANTOS

Mestranda no Programa de Pós-Graduação de Letras da Universidade Estadual de Maringá (UEM). Licenciada em Língua Portuguesa e Inglês, pela Universidade Federal do Mato Grosso do Sul- Campus do Pantanal (UFMS-CPAN).

E-mail: marianassantos687@gmail.com

Rauer Ribeiro RODRIGUES

Doutor em Estudos Literários pela UNESP, com pós-doutorado na UERJ. Atua no PPG-Letras e no PROFLETRAS do Campus de Três Lagoas da Universidade Federal de Mato Grosso do Sul (UFMS). Professor de Literatura Brasileira Contemporânea.

E-mail: rauer.rodrigues@ufms.br. 